\title{
Professional identity and mental health of rural-oriented tuition-waived medical students in Anhui Province, China
}

\author{
Ling Wang $^{1 \dagger}$, Yuwei Yang ${ }^{1 \dagger}$, Jimin Zhu ${ }^{2}$, Hong Xie ${ }^{3}$, Chunxiao Jiang ${ }^{1}$, Chi Zhang ${ }^{1}$, Jie Li ${ }^{4}$ and Fen Huang ${ }^{1,5^{*}}$
}

\begin{abstract}
Background: The shortage of primary care physicians in rural China is an enduring problem with serious implications for access to care. In response to the shortage in health workforce in rural areas, China government has launched the rural-oriented tuition-waived medical education (RTME) programme since 2010, aiming to train more general practitioners to address the rural health workforce requirements in middle and west areas. This study aims to investigate the prevalence of mental illness and the level of professional identity in the rural-oriented tuition-waived medical students (RTMSS), and to explore the impact of the RTMSs' professional identity and related cognition and satisfaction with the RTME programme on mental health.

Methods: We conducted a descriptive, cross-sectional study. A total of 1103 RTMSs and 1095 non-oriented medical students from seven medical universities (colleges) in Anhui province completed a demographic questionnaire, the Depression, Anxiety, Stress Scales and the Professional Identity Questionnaire for Undergraduate Students. Cognition and satisfaction with the RTME programme of the RTMSs were collected. Multiple linear regression analysis was used to analyze the data.
\end{abstract}

Results: The prevalence of depression, anxiety, and stress in RTMSs were 11.8, 22.9 and 3.4\%, respectively. The mean total scores of the Professional Identity Questionnaire for Undergraduate Students were $3.58(S D=0.61)$. Results of multiple linear regression model indicated that students who are dissatisfied with targeted primary healthcare institution are likely to suffer from depression and anxiety; moreover, students who enrolled in the rural-oriented tuition-waived medical education programme due to economic reason are more likely to suffer from anxiety. Furthermore, a significant positive correlation was found between professional identity and mental health.

Conclusions: Providing better information about the RTME programme prior to enrollment and improving the students' cognition of the policy's effectiveness and the social value of rural healthcare work may contribute to improving the professional identity of the RTMSs. Meanwhile, a significant positive association was found between professional identity and mental health. This is a new perspective that shows that developing and improving professional identity may help medical students reduce the risk of psychological illness.

Keywords: RTME, Medical students, Professional identity, Mental health

\footnotetext{
* Correspondence: fenh@ahmu.edu.cn

${ }^{+}$Ling Wang and Yuwei Yang contributed equally to this work and should be considered as co-first authors.

'Department of Epidemiology and Biostatistics, School of Public Health, Anhui Medical University, No. 81 Meishan Road, Shushan Districts, Hefei 230032, Anhui, China

${ }^{5}$ Central Laboratory of Preventive Medicine, School of Public Health, Anhui Medical University, 81 Meishan Road, Shushan District, Hefei 230032, Anhui, China

Full list of author information is available at the end of the article
}

(c) The Author(s). 2019 Open Access This article is distributed under the terms of the Creative Commons Attribution 4.0 International License (http://creativecommons.org/licenses/by/4.0/), which permits unrestricted use, distribution, and reproduction in any medium, provided you give appropriate credit to the original author(s) and the source, provide a link to the Creative Commons license, and indicate if changes were made. The Creative Commons Public Domain Dedication waiver (http://creativecommons.org/publicdomain/zero/1.0/) applies to the data made available in this article, unless otherwise stated. 


\section{Background}

Despite decades of strategies designed to reduce the disparity in the supply of physicians between rural and urban areas, geographic maldistribution has remained a persistent feature of the physician workforce in China $[1,2]$. Nearly three times as many healthcare professionals per 100,000 people practice in urban areas as in small rural areas. By contrast, approximately $43 \%$ of the population lives in rural China, and only approximately $12 \%$ of the physicians practice in rural locations [3]. The shortage of rural healthcare professionals has become a bottleneck that seriously restricts the further improvement of service and level of primary medical institutions.

In response to the shortage in health workforce in rural areas, China has proposed numerous health workforce development plans or policies, including the rural-oriented tuition-waived medical education (RTME) programme initiated and promoted since 2010. This programme aims to train additional general practitioners to address the rural health workforce requirements in the middle and west areas. In China, the three-tier health service delivery system consists of county hospitals, township health centers, and village clinics in rural areas, providing basic health care to the rural population. Township hospitals, as the main provider of rural primary healthcare services, play a critical role in serving the majority of approximately 590 million people in the rural areas of China [4-6]. However, the township hospitals are severely understaffed [7]. These hospitals have difficulty recruiting sufficient healthcare professionals or can employ only healthcare professionals with limited education. Therefore, the RTME programme was implemented. This programme aimed to enroll medical students mainly from rural areas to work in township hospitals for 6 years after they graduation. In this programme, the medical students would sign a contract with the medical training school and local health administrative department. The government would waive the related tuition fee for the students and provide them with a certain amount of living allowance during their studies in designated medical universities. Although the RTME programme has contributed considerably to the rural workforce in the past few years, a recent survey showed that only approximately $1.6 \%$ of graduates are willing to return to rural communities [8]. Obstacles that discourage them from practicing as a rural general practitioner include limited professional development prospect, unsound medical equipment and facilities, and inadequate financial remuneration, thereby simultaneously influencing the professional identity of RTMSs.

Physicians' professional identity is usually defined as 'the integration of the knowledge, skills, values, and behaviors of a doctor with one's own unique identity and core values' $[9,10]$.. Professional identity, or how a doctor thinks of himself or herself as a doctor, is considered to be a key factor in the ability of health professionals to provide high-quality care to improve patient outcomes $[11,12]$ and is believed to mediate the negative effects of a high-stress workplace [13] and improve clinical performance $[14,15]$ and job retention $[16,17]$. A longitudinal cohort study conducted on the junior doctors, which is a critical period of transition from medical students to professional doctors, suggested that professional identity was significantly negatively related to burnout, including personal and work-related burnout. [18]. Thus, improved understanding of the professional identity of medical students provides an important contribution to improving mental health and career satisfaction in the professional practice.

Concerns surrounding mental health in the medical profession have been extensively discussed in recent years. The demands and pressure of medical training have been documented well to pose a huge challenge to the personal well-being of physicians [19]. These demands and pressures frequently lead to many negative consequences, such as poor academic performance [20], increased rates of substance use [21], and even suicide [22]. Thus, the psychological well-being of medical students is crucial not only for the medical students themselves, but also for the quality of health care they will provide and the doctor-patient relationship in the future.

For the present study, we aim to investigate all the RTMSs in Anhui Province to evaluate professional identity and mental health and identify potential influencing factors.

\section{Methods}

\section{Study design and participants}

This cross-sectional study was conducted among all RTMSs from seven medical universities (colleges) in Anhui Province using an anonymous self-administered questionnaire. For comparison, 1103 RTMSs and 1095 non-oriented medical students from the same universities (colleges) were invited to participate in this study. These universities (colleges) offer two education formats, namely, 3-year junior college study programme and 5 -year Bachelor of Medicine degree programme. A bachelor's degree study programme, which is divided into three-preclinical years followed by two clinical years. Similarly, the junior college study programme comprises of two pre-clinical years followed by one clinical year. This study has been reviewed and approved by the Ethics Committee of Anhui Medical University.

\section{Measure \\ Professional identity}

The Professional Identity Questionnaire for Undergraduate Students (PIQUS) was compiled in a Chinese language by Qin Panbo to measure professional identity among the undergraduate students [23]. This instrument contains 23 
items and yields scores on the following four dimensions: cognition (five items), emotionality (eight items), behavior (six items) and fitness (four items). Items are accessed on a 5 -point Likert scale ("complete conformity" $=5$, "conformity" $=4$, "neutral" $=3$, "inconformity" $=2$, and "complete inconformity" $=1$ ). The total scores are calculated by the sum of scores of each question divided by the total number of questions; high scores indicate high level of professional identity.

\section{Mental health}

Mental health problems were measured using a validated Chinese version of the Depression Anxiety Stress Scale-21 (DASS-21). DASS-21 is a set of three self-administered subscales (seven questions each) designed to measure the negative emotional states of depression, anxiety, and stress. The 21-item instrument asked respondents to rate the presence of these items of a symptom over the past week on a 4-point Likert scale with scores from 0 to 3 . The scores of each subscale is equal to the sum of seven corresponding items and ranges from 0 to 21. A high subscale score indicates an unfavorable psychological status. Previous studies have demonstrated that the Chinese version of DASS-21 has excellent psychometric properties, with an overall Cronbach's alpha coefficient of 0.89 [24].

\section{Demographic characteristics, cognition and satisfaction with the RTME programme}

Demographic factors include age, gender, education level, location of hometown, family monthly income, father's occupation and education, and mother's occupation and education. Cognition of the RTME programme consisted of the following questions: (1) why did you decide to enroll in the programme? (2) Do you understand the conditions of the policy before enrolling? (3) Do you understand the conditions of targeted primary health organization? (4) Do you understand the Healthy China 2030 Plan Outline? (5) Do you understand the equitable access to basic public health services? (6) What was your cognition of the RTME programme? Satisfaction with the RTME programme included four items as following: satisfaction with targeted primary health organization, six years' service period, living allowance and standardized training.

\section{Data analysis}

The statistical analysis was performed using SPSS for Windows (version 23.0; SPSS Inc., Chicago, IL, USA). All study variables were carried out with a descriptive analysis. Quantitative variables were described as mean \pm standard error, whereas categorical variables were expressed as frequencies. In this study, the independent variables included demographic characteristics, cognition and satisfaction with the RTME programme; the dependent variables were professional identity and mental health. Multiple linear regression analysis was conducted to explore the factors affecting the professional identity. In Model 1, the impacts of the demographic characteristics were assessed. The factors of cognition of the RTME programme were added in Model 2, and the satisfaction with the RTME programme were further added in Model 3. Multivariate stepwise linear regression analysis was applied to access the factors associated with mental health. A $P$-value less than 0.05 was regarded as statistically significant.

\section{Results}

Demographic characteristics

The mean age of the RTMSs was 20.5 years old. The profile of the sample studied was predominantly female (56.5\%) and family monthly income of more than 5000 yuan (19.1\%). $84.7 \%$ of the RTMSs were from rural areas.. Within the non-oriented medical student group, fewer than half of the respondents were male (43.7\%), and $31.2 \%$ of population had a family income of more than 5000 yuan per month. Furthermore, $67.4 \%$ of the non-oriented medical students were from rural areas. The other personal characteristics were listed in Table 1.

\section{Cognition and satisfaction with the RTME programme}

Table 2 summarized the cognition and satisfaction with the RTME programme of the RTMSs. Prior to enrolment, $13.2 \%$ of the RTMSs did not understand the policy conditions, whereas $36.3 \%$ of the RTMSs understood the policy very well or relatively well. The majority $(44.4 \%)$ of the RTMSs selected the programme due to the recommendation of family members or teachers, whereas $17.6 \%$ selected the programme because of personal interests. In terms of the view on the RTME programme, $45.4 \%$ believed that this programme limits personal career development, and only $8.4 \%$ believed this programme will help achieve personal value. In terms of satisfaction with the RTME programme, $47.6 \%$ of the RTMSs were satisfied with targeted primary health organization, whereas $50.9 \%$ were satisfied with the living allowance; however, the percentage of satisfaction with 6 years' service period was the lowest at only $34.0 \%$.

\section{Professional identity and influencing factors}

The mean total scores of the professional identity of the RTMSs were $3.58 \pm 0.61$, and the scores of the other dimension are listed in Table 3. The total scores of professional identity did not exhibit significant differences between the two groups $(P=0.058)$. In terms of cognition and emotionality dimension, the scores were significantly lower in the RTMSs than in the non-oriented medical students. Appendix 1 in the supplementary material shows the absolute frequency of ratings per item of the PIQUS. 
Table 1 Demographic characteristics of the participants

\begin{tabular}{|c|c|c|}
\hline \multirow{2}{*}{$\begin{array}{l}\text { Demographic } \\
\text { characteristic }\end{array}$} & \multicolumn{2}{|c|}{ No. (\%) of Participants } \\
\hline & $\begin{array}{l}\text { RTMSs } \\
(n=1103)\end{array}$ & $\begin{array}{l}\text { Non-oriented medical students } \\
(n=1095)\end{array}$ \\
\hline \multicolumn{3}{|l|}{ Gender } \\
\hline Male & $478(43.5)$ & $479(43.7)$ \\
\hline Female & $621(56.5)$ & $616(56.3)$ \\
\hline \multicolumn{3}{|l|}{ Educational level } \\
\hline Undergraduate & $724(65.6)$ & $720(65.8)$ \\
\hline Junior college & $379(34.4)$ & $375(34.2)$ \\
\hline \multicolumn{3}{|l|}{ Academic years } \\
\hline Pre-clinical & $707(64.1)$ & $699(63.8)$ \\
\hline Clinical & $396(35.9)$ & $396(36.2)$ \\
\hline \multicolumn{3}{|l|}{ Location of hometown } \\
\hline Rural & $934(84.7)$ & $738(67.4)$ \\
\hline Urban & $162(14.7)$ & $357(32.6)$ \\
\hline \multicolumn{3}{|l|}{ Family monthly income (RMB) } \\
\hline$\leq 5000$ & $887(80.9)$ & $751(68.8)$ \\
\hline$>5000$ & $210(19.1)$ & $341(31.2)$ \\
\hline \multicolumn{3}{|l|}{ Father's occupation } \\
\hline Worker & $313(28.5)$ & $305(27.9)$ \\
\hline Farmer & $433(39.4)$ & $326(29.9)$ \\
\hline Businessman & $177(16.1)$ & $220(20.1)$ \\
\hline Professionals & $116(10.5)$ & $158(14.5)$ \\
\hline Others & $61(5.5)$ & $83(7.6)$ \\
\hline \multicolumn{3}{|l|}{ Father's education } \\
\hline Primary school or below & $251(22.8)$ & $180(16.5)$ \\
\hline Junior high school & $534(48.5)$ & $531(48.5)$ \\
\hline Senior high school & $224(20.3)$ & $229(20.9)$ \\
\hline Postsecondary or above & $92(8.4)$ & $154(14.1)$ \\
\hline \multicolumn{3}{|l|}{ Mother's occupation } \\
\hline Worker & $208(19.0)$ & $201(18.4)$ \\
\hline Farmer & $535(48.8)$ & $404(37.0)$ \\
\hline Businessman & $188(17.1)$ & $254(23.2)$ \\
\hline Professionals & $54(4.9)$ & $96(8.8)$ \\
\hline Others & $112(10.2)$ & $138(12.6)$ \\
\hline \multicolumn{3}{|l|}{ Mother's education } \\
\hline Primary school or below & $523(47.6)$ & $421(38.5)$ \\
\hline Junior high school & $413(37.6)$ & $411(37.6)$ \\
\hline Senior high school & $126(11.5)$ & $175(16.0)$ \\
\hline Postsecondary or above & $37(3.4)$ & $86(7.9)$ \\
\hline
\end{tabular}

In multiple linear regression analysis, Model 1 showed the following findings: junior college students were apparently inclined to a higher level of professional identity than undergraduate students $(\beta=0.054, P<0.001)$; students at $\mathrm{s}$ clinical internship had a lower level of
Table 2 Cognition and satisfaction with the RTME programme of the RTMSs

\begin{tabular}{|c|c|}
\hline Variable & No.(\%) of the Participants \\
\hline \multicolumn{2}{|c|}{ Reasons for enrolment in the RTME programme } \\
\hline $\begin{array}{l}\text { Recommendations of family members } \\
\text { or teachers }\end{array}$ & $489(44.4)$ \\
\hline Economic reasons & $97(8.8)$ \\
\hline Serve the local people & $102(9.3)$ \\
\hline Guaranteed employment & $82(7.4)$ \\
\hline Personal interests & $194(17.6)$ \\
\hline By mistake & $137(12.4)$ \\
\hline \multicolumn{2}{|l|}{$\begin{array}{l}\text { Understanding the conditions of policy } \\
\text { before enrolling }\end{array}$} \\
\hline Don't understand & $146(13.2)$ \\
\hline Generally understand & $556(50.5)$ \\
\hline Very or relatively well & $400(36.3)$ \\
\hline \multicolumn{2}{|l|}{$\begin{array}{l}\text { Understanding the conditions of targeted } \\
\text { primary health organization }\end{array}$} \\
\hline Don't understand & $334(30.3)$ \\
\hline Generally understand & $561(50.9)$ \\
\hline Very or relatively well & $207(18.8)$ \\
\hline \multicolumn{2}{|l|}{$\begin{array}{l}\text { Understand the Healthy China } 2030 \\
\text { Plan Outline }\end{array}$} \\
\hline Yes & $91(8.3)$ \\
\hline No & $1011(91.7)$ \\
\hline \multicolumn{2}{|l|}{$\begin{array}{l}\text { Understand the equitable access to basic } \\
\text { public health services }\end{array}$} \\
\hline Yes & $245(22.2)$ \\
\hline No & $858(77.8)$ \\
\hline \multicolumn{2}{|l|}{ View on the RTME programme } \\
\hline Limiting personal career development & $501(45.4)$ \\
\hline Have a stable work & $436(39.5)$ \\
\hline Achieve personal value & $93(8.4)$ \\
\hline Other & $73(6.6)$ \\
\hline \multicolumn{2}{|l|}{$\begin{array}{l}\text { Satisfaction with targeted primary } \\
\text { health organization }\end{array}$} \\
\hline Yes & $525(47.6)$ \\
\hline No & $578(52.4)$ \\
\hline \multicolumn{2}{|l|}{ Satisfaction with six years' service period } \\
\hline Yes & $375(34.0)$ \\
\hline No & $728(66.0)$ \\
\hline \multicolumn{2}{|l|}{ Satisfaction with living allowance } \\
\hline Yes & $561(50.9)$ \\
\hline No & $542(49.1)$ \\
\hline \multicolumn{2}{|l|}{ Satisfaction with standardized training } \\
\hline Yes & $961(87.4)$ \\
\hline No & 139 (12.6) \\
\hline
\end{tabular}


Table 3 The scores of professional identity and DASS-21 of the participants

\begin{tabular}{|c|c|c|c|}
\hline & RTMSs & Non-oriented medical students & $P$ value \\
\hline \multicolumn{4}{|c|}{ Professional identity } \\
\hline Total scores & $3.58(0.61)$ & $3.63(0.67)$ & 0.058 \\
\hline Cognition & $3.65(0.67)$ & $3.72(0.72)$ & 0.007 \\
\hline Emotionality & $3.63(0.81)$ & $3.74(0.82)$ & 0.002 \\
\hline Behavior & $3.62(0.68)$ & $3.61(0.78)$ & 0.631 \\
\hline Fitness & $3.35(0.76)$ & $3.35(0.82)$ & 0.994 \\
\hline \multicolumn{4}{|l|}{ DASS-21 } \\
\hline Depression & $4.29(4.06)$ & $4.70(4.55)$ & 0.028 \\
\hline Anxiety & $4.66(3.85)$ & $5.05(4.51)$ & 0.027 \\
\hline Stress & $5.68(4.20)$ & $6.05(4.74)$ & 0.054 \\
\hline
\end{tabular}

professional identity $(\beta=-0.169, P<0.001)$; students with family monthly income of 5000 yuan or above were more likely to have lower level of professional identity $(\beta=-0.056, P=0.023)$.

Model 2 showed that, compared with the students who enrolled in the RTME programme due to recommendations of family members or teachers, students whose policy choice motivation was to serve the local people $(\beta=0.174, P=0.006)$ or personal interests $(\beta=0.032, P<0.001)$ had a higher level of professional identity; nevertheless, those who enrolled in the RTME programme by mistake presented a lower level of professional identity $(\beta=-0.152, P=0.007)$; compared with those who did not understand the policy prior to enrolment, students who generally understand the policy $(\beta=0.168, P=0.004)$ or understanding the policy very or relatively well $(\beta=0.277$, $P<0.001)$ were more inclined to a high level of professional identity; furthermore, students who understood the Healthy China 2030 Plan Outline were more likely to have higher level of professional identity than students who did not understand the policy; compared with those who believe that the RTME programme limits personal career development, students who considered that the programme can help achieve personal value $(\beta=0.296, P<0.001)$ or offer a stable work $(\beta=0.188, \quad P<0.001)$ had higher level of professional identity. Model 3 further showed that, students who were unsatisfied with the six-year service period $(\beta=-0.124, P=0.004)$, living allowance $(\beta=-0.117, P=0.003)$, and standardized training $(\beta=-0.172, P=0.001)$ were apparently inclined to a low level of professional identity (Table 4$)$.

\section{Mental health and influencing factors}

In our population, anxiety symptoms were highly prevalent among the RTMSs. The prevalence of depression, anxiety, and stress symptoms was at 11.8, 22.9 and 3.4\%, correspondingly. In addition to stress, the scores of depression and anxiety were significantly lower in the RTMSs than in the non-oriented medical students. The multiple stepwise linear regression showed the following results: students with high level of professional identity were apparently inclined to better mental health; students involved in clinical internship were more likely to suffer from psychological disorders; junior college students were more inclined to suffer from depression $(\beta=1.457, P<0.001)$ and anxiety $(\beta=1.375, P<0.001)$ than undergraduate students; students who were unsatisfied with the targeted primary health organizations were more likely to suffer from depression $(\beta=0.522, P=0.014)$ and anxiety $(\beta=0.529, P=0.016)$. In addition, the students who applied for the RTME programme due to economic reason were more likely to suffer from anxiety than those who enrolled in the RTME programme due to recommendations of family members or teachers $(\beta=0.942, P=0.013)$ (Table 5).

\section{Discussion \\ Professional identity in RTMSs}

In terms of professional identity, no significant difference was found between RTMSs and non-oriented medical students. Nevertheless, our findings are inconsistent with other domestic studies, which showed that the RTMSs have a lower level of professional identity than the non-oriented medical students [25, 26]. These findings suggested that this phenomenon is frequently the result of personal, professional, and contextual factors, including heavy workload, lack of professional development space, geographic isolation, and concerns regarding educational, and employment opportunities for children. Given that all the RTMSs in Anhui Province were investigated, the result of the current study may have improved generalizability. Furthermore, in terms of cognition and emotionality dimension, the scores of the RTMSs were significantly lower than those of non-oriented medical students. According to the PIQUS, the dimension of cognition reflects the understanding of social value, career prospects and academic requirement of their major, and the dimension of emotionality reflects the satisfaction with their major, and whether they are willing to devote themselves to the profession after graduation. This result indicates that it's essential for health professions educators to take measures to enhance the professional identity of RTMSs.

The need to connect theory with practice is an increasingly recognized aspect of medical education [27, 28]. Disjunction between the two may lead to the students feeling unrealistic and powerless. According to one study, students' concepts of themselves as future doctors evolved quickly as they came into contact with patients [29]. Communications with other healthcare professionals also play an important role in the professional identity 
Table 4 Multiple linear regression on the RTMSs' PIQUS ${ }^{a}$ total scores

\begin{tabular}{|c|c|c|c|c|c|c|}
\hline \multirow[t]{2}{*}{ Explanatory variables } & \multicolumn{2}{|l|}{ Model1 } & \multicolumn{2}{|l|}{ Model 2} & \multicolumn{2}{|l|}{ Model 3} \\
\hline & $\beta$ (Std. Error) & $P$ value & $\beta$ (Std. Error) & $P$ value & $\beta$ (Std. Error) & $P$ value \\
\hline \multicolumn{7}{|c|}{ Education level (Reference value:Undergraduate) } \\
\hline Junior college & $0.254(0.041)$ & $<0.001$ & $0.126(0.041)$ & 0.002 & $0.079(0.041)$ & 0.056 \\
\hline \multicolumn{7}{|c|}{ Academic years (Reference value: Pre-clinical) } \\
\hline Clinical & $-0.169(0.041)$ & $<0.001$ & $-0.109(0.039)$ & 0.006 & $-0.061(0.039)$ & 0.124 \\
\hline \multicolumn{7}{|c|}{ Family monthly income (Reference value: $\leq 5000$ ) } \\
\hline$>5000$ & $-0.056(0.024)$ & 0.023 & $-0.114(0.044)$ & 0.009 & $-0.094(0.043)$ & 0.029 \\
\hline \multicolumn{7}{|c|}{$\begin{array}{l}\text { Reasons for enrolment in the RTME programme } \\
\text { (Reference value: Recommendations of } \\
\text { family members or teachers) }\end{array}$} \\
\hline Economic reasons & & & $-0.056(0.063)$ & 0.376 & $-0.049(0.062)$ & 0.432 \\
\hline Serve the local people & & & $0.174(0.063)$ & 0.006 & $0.191(0.061)$ & 0.002 \\
\hline Guaranteed employment & & & $-0.058(0.067)$ & 0.389 & $-0.061(0.066)$ & 0.360 \\
\hline Personal interests & & & $0.232(0.048)$ & $<0.001$ & $0.220(0.047)$ & $<0.001$ \\
\hline By mistake & & & $-0.152(0.056)$ & 0.007 & $-0.131(0.055)$ & 0.018 \\
\hline \multicolumn{7}{|c|}{$\begin{array}{l}\text { Understanding the conditions of policy before } \\
\text { enrolling (Reference value: Don't understand) }\end{array}$} \\
\hline Generally understand & & & $0.168(0.059)$ & 0.004 & $0.142(0.058)$ & 0.014 \\
\hline Very or relatively well & & & $0.277(0.066)$ & $<0.001$ & $0.221(0.065)$ & $<0.001$ \\
\hline \multicolumn{7}{|c|}{$\begin{array}{l}\text { Understanding the conditions of targeted primary } \\
\text { health organization (Reference value: Don't understand) }\end{array}$} \\
\hline Generally understand & & & $0.032(0.044)$ & 0.468 & $0.033(0.043)$ & 0.445 \\
\hline Very or relatively well & & & $-0.074(0.064)$ & 0.248 & $-0.081(0.064)$ & 0.201 \\
\hline \multicolumn{7}{|c|}{$\begin{array}{l}\text { Understand the Healthy China } 2030 \text { Plan Outline } \\
\text { (Reference value: No) }\end{array}$} \\
\hline Yes & & & $0.064(0.069)$ & 0.352 & $0.074(0.068)$ & 0.275 \\
\hline \multicolumn{7}{|c|}{$\begin{array}{l}\text { Understand the Equitable access to basic public health services } \\
\text { (Reference value: No) }\end{array}$} \\
\hline Yes & & & $0.132(0.047)$ & 0.005 & $0.100(0.046)$ & 0.029 \\
\hline \multicolumn{7}{|c|}{$\begin{array}{l}\text { View on the RTME programme } \\
\text { (reference value: Limiting personal career development) }\end{array}$} \\
\hline Have a stable work & & & $0.188(0.039)$ & $<0.001$ & $0.087(0.041)$ & 0.033 \\
\hline Achieve personal value & & & $0.296(0.067)$ & $<0.001$ & $0.176(0.068)$ & 0.009 \\
\hline Other & & & $0.213(0.070)$ & 0.002 & $0.157(0.069)$ & 0.024 \\
\hline \multicolumn{7}{|c|}{$\begin{array}{l}\text { Satisfaction with targeted primary health organization } \\
\text { (Reference value: Yes) }\end{array}$} \\
\hline No & & & & & $-0.060(0.042)$ & 0.156 \\
\hline \multicolumn{7}{|c|}{ Satisfaction with six years' service period (Reference value: Yes) } \\
\hline No & & & & & $-0.124(0.043)$ & 0.004 \\
\hline \multicolumn{7}{|c|}{ Satisfaction with living allowance (Reference value: Yes) } \\
\hline No & & & & & $-0.117(0.039)$ & 0.003 \\
\hline \multicolumn{7}{|c|}{ Satisfaction with standardized training (Reference value: Yes) } \\
\hline No & & & & & $-0.172(0.052)$ & 0.001 \\
\hline
\end{tabular}

PIQUS Professional Identity Questionnaire for Undergraduate Students

formation of the student doctors. For instance, the morning report, where students can directly interact with the senior doctors, is an excellent location for exchanging clinical experience and the popularization of medical knowledge [30]. One pedagogical approach that fosters the active involvement of the individual in the creation of their professional identity is narrative reflection. For trainee doctors, they could tell and retell the story of their 
Table 5 Multiple stepwise linear regression of RTMSs' mental health

\begin{tabular}{|c|c|c|}
\hline & $\beta$ (Std. error) & $P$ value \\
\hline \multicolumn{3}{|l|}{ Depression } \\
\hline Professional identity & $-1.591(0.181)$ & $<0.001$ \\
\hline \multicolumn{3}{|c|}{ Education level (Reference value: Undergraduate) } \\
\hline Junior college & $1.457(0.251)$ & $<0.001$ \\
\hline \multicolumn{3}{|c|}{ Academic years (Reference value: Pre-clinical) } \\
\hline Clinical & $3.083(0.240)$ & $<0.001$ \\
\hline \multicolumn{3}{|c|}{$\begin{array}{l}\text { Satisfaction with targeted primary health organization } \\
\text { (Reference value: Yes) }\end{array}$} \\
\hline No & $0.552(0.224)$ & 0.014 \\
\hline \multicolumn{3}{|l|}{ Anxiety } \\
\hline Professional identity & $-1.169(0.180)$ & $<0.001$ \\
\hline \multicolumn{3}{|c|}{ Education level (Reference value: Undergraduate) } \\
\hline Junior college & $1.375(0.247)$ & $<0.001$ \\
\hline \multicolumn{3}{|c|}{ Academic years (Reference value: Pre-clinical) } \\
\hline Clinical & $2.689(0.236)$ & $<0.001$ \\
\hline \multicolumn{3}{|c|}{$\begin{array}{l}\text { Satisfaction with targeted primary health organization (Reference } \\
\text { value: Yes) }\end{array}$} \\
\hline No & $0.529(0.218)$ & 0.016 \\
\hline \multicolumn{3}{|c|}{$\begin{array}{l}\text { Reasons for enrolment in the RTME programme (Reference value } \\
\text { Recommendations of family members or teachers) }\end{array}$} \\
\hline Economic reason & $0.942(0.377)$ & 0.013 \\
\hline \multicolumn{3}{|l|}{ Stress } \\
\hline Professional identity & $-1.355(0.188)$ & $<0.001$ \\
\hline \multicolumn{3}{|c|}{ Academic years (Reference value: Pre-clinical) } \\
\hline Clinical & $3.412(0.237)$ & $<0.001$ \\
\hline
\end{tabular}

experiences. Self-reflection of an individual's thoughts, behavior and experience within their academic and clinical education promotes that person to develop their own understanding by which to lives as doctors [31]. With regard to the family economic factors, the students from the families with monthly income of more than 5000 yuan were found to be associated with weaken professional identity. This may be due to the fact that students from more wealthy family might give more priority to monetary income and that work in rural setting could not fulfill their will [32]. Many theoretical studies have suggested that intrinsic motivation strongly affects the job satisfaction of students [33, 34], however, in our study, only less than one-fifth of the RTMSs selected the programme because of personal interest. This study further verified this viewpoint. The students who selected the programme due to personal interests or serving the local people showed a higher level of professional identity than the students who enrolled in the programme because of recommendations of family members or teachers. Therefore, teachers and parents should fully respect the decisions of students and provide guidance on voluntarily applying for college entrance examination based on the personality traits and interests of students. In addition, students who have positive cognition of the RTME programme were more likely to devote themselves to primary healthcare service with high level of professional identity. The RTMSs who understand the policy of the RTME programme prior to enrolment or the equitable access to basic public health services were more likely to have a positive attitude towards the profession. Policy satisfaction (satisfaction with the six-year service period, living allowance, and standardized training) was significantly associated with professional identity. Therefore, the admission departments must strength the publicity of the RTME programme and introduce a specific content of the policy to students and parents in admission presentations to recruit high-quality students who aspire to serve the primary healthcare institutions. Meanwhile, the interview before enrolling can also be used to assess the applicants' suitability as a supplementary measure, which may include their value, cognition, and other personality characteristics, so as to select qualified medical students who have a clear understanding of RTME policy and feel satisfied. Moreover, medical schools are responsible for conducting regular ideological and professional development education to enhance their cognition of current status and social value of rural healthcare, thus strengthening the noble mission and social responsibility for retaining primary healthcare workers.

\section{Mental health in RTMSs}

In our study, the prevalence of depression, anxiety and stress were apparently lower than those in other studies using similar instruments among medical students in different countries [35-39]. Furthermore, the scores of depression and anxiety were significantly lower than those of non-oriented medical students, thereby indicating that the RTMSs have an improved psychological health status. For the RTMSs, we assumed that employment security, and the absence of academic financial burden may contribute to moderating the psychological distress. For example, a longitudinal population-based study demonstrated that exposure to poverty in childhood was found to be positively associated with many mental health problems in adolescence, such as depression [40]. Free tuition and a certain amount of living allowance during their studies relieves their family financial burden, and provides the economic support for professional learning. In addition, they need not worry about employment after graduation. To some extent, these factors may contribute to improving RTMSs' mental health. However, additional studies on the prevalence of psychological distress in RTMSs are required to provide a comparison.

In the present study, students who underwent clinical training exhibit higher levels of psychological distress 
than those in pre-clinical years. This finding may be attributed to the contradiction between the desire to live in a metropolitan city and the reality of returning to primary healthcare institution after graduation. Moreover, the junior college students had a higher level of depression and anxiety than the undergraduate students. These students may feel inferior and worry that their knowledge is difficult to reconcile with job demand after entering the clinical practice. In addition, the satisfaction with targeted primary healthcare institutions was significantly associated with depression and anxiety. Therefore, strengthening the publicity of the RTME programme prior to enrolment and ensuring that these students can serve the local primary healthcare organizations may contribute to improving the mental health of the RTMSs. We also reported that students who enrolled in the RTME programme due to economic reason are likely to suffer from anxiety. For these students, the government could provide certain financial support to help them complete their studies and devote themselves to grassroots service after graduation with optimal psychological status.

This study showed statistically positive correlation between professional identity and mental health of the RTMSs. Our results indicated that the RTMSs with a higher level of professional identity has lower levels of psychological distress. By contrast, students who are dissatisfied with the profession may have increased negative emotions, such as complaints and tiredness in their study life, feelings of confusion for their future, or lacking explicit life plans, thereby making them likely to suffer from psychological disorders. Therefore, this study showed a new perspective which developing and improving professional identity may be beneficial for the RTMSs in promoting mental health.

\section{Strengths of the study}

The current study is the first attempt to evaluate the professional identity and mental health in the RTMSs. The results of our study may be useful to the mental health prevention and promotion of professional identity for the RTMSs. Second, the sample size was adequate to assess the two constructs with favorable representation due to the investigating of all the RTMSs in Anhui Province. Third, we used DASS-21 to measure mental health problems and assessed the prevalence of depression, anxiety, and stress symptoms together. Finally, we found a positive association between professional identity and mental health of the RTMSs, thus indicating that subjects with low levels of professional identity may be susceptible to mental health problems.

\section{Limitations of the study}

We recognized several important limitations. Considering that this study was based on the results obtained from a self-administrated questionnaire, recall bias should be included. Moreover, the results of students' understanding of the RTME policy were based on self-reporting and were mostly subjective assessment. Although certain sociodemographic factors were included in the study, other factors, such as lifestyle and family history of psychological disorders, were disregarded. These factors should be considered in future research. Given that we conducted an observational study, no causal inferences can be drawn. Further longitudinal studies are necessary to elucidate the long-standing change in professional identity and mental health problems in this population.

\section{Conclusions}

Given that the fundamental goal of medical education is to shape and cultivate students' professional identity, appropriate strategies should be implemented. The policy publicity should be strengthened, and educators should improve the students' cognition of the policy's effectiveness and the social value of rural healthcare work, which could motivate students' desire to perform rural healthcare work. Providing sound medical infrastructure and increasing remuneration in rural medical institutions may also benefit to the improvement of RTMSs' professional identity. Furthermore, we also reported a positive association between students' professional identity and mental health, this is a new perspective that shows that developing professional identity may prove helpful for medical students in promoting mental health.

\section{Appendix 2}

To produce competent healthcare professionals for rural area, the Chinese government has launched a rural-oriented uition-waived medical education (RTME) programme since 2010. This programme aims to enroll medical students mainly from rural areas to work in township hospitals for 6 years after graduation. Medical universities and junior colleges are responsible for undertaking the education programme. The universities offer the 5 years medical education programme, while the junior colleges provide the 3 years medical education programme. Graduates of the 5-year programme earn a bachelor's degree, and graduates of the 3-year programme receive an associate degree.

Each province which undertaking the rural-oriented tuition-waived medical education (RTME) programme has a quota every year. Applicants for the RTME programme should meet the following requirements: (1) students who graduates from high school are willing to devote themselves to the rural healthcare work; (2) the registered permanent residence of students and their legal guardians should be in the rural area, in addition, 


\section{Appendix 1}

Table $\mathbf{6}$ The absolute frequency of ratings per item of the professional identity Questionnaire for undergraduate students

\begin{tabular}{|c|c|c|c|c|}
\hline \multirow[t]{2}{*}{ Sub-dimension } & \multirow[t]{2}{*}{ Item } & \multicolumn{3}{|l|}{ Ratings (\%) } \\
\hline & & Inconformity & Neutral & Conformity \\
\hline \multirow[t]{5}{*}{$\overline{C o g n i t i o n}$} & $\begin{array}{l}\text { I know the requirements } \\
\text { for learners of the majors }\end{array}$ & 9.7 & 21.2 & 69.1 \\
\hline & $\begin{array}{l}\text { I know the employment } \\
\text { situations of my major }\end{array}$ & 12.8 & 24.1 & 63.1 \\
\hline & $\begin{array}{l}\text { I know the status of my } \\
\text { major in school }\end{array}$ & 8.8 & 20.3 & 70.9 \\
\hline & $\begin{array}{l}\text { I know the evaluation of } \\
\text { my major outside }\end{array}$ & 12.2 & 32.2 & 55.6 \\
\hline & $\begin{array}{l}\text { I know the profession } \\
\text { in general }\end{array}$ & 8.0 & 19.5 & 72.5 \\
\hline \multicolumn{5}{|l|}{ Emotionality } \\
\hline & $\begin{array}{l}\text { I am willing to engage in } \\
\text { job related to my major }\end{array}$ & 10.3 & 18.7 & 71.1 \\
\hline & $\begin{array}{l}\text { I have accepted my } \\
\text { profession in my heart }\end{array}$ & 10.3 & 17.9 & 71.9 \\
\hline & $\begin{array}{l}\text { I have never thought } \\
\text { about changing my major }\end{array}$ & 20.8 & 18.3 & 60.9 \\
\hline & $\begin{array}{l}\text { I have a positive evaluation } \\
\text { of my major }\end{array}$ & 9.4 & 16.2 & 74.3 \\
\hline & $\begin{array}{l}\text { I have faith in the } \\
\text { development prospect } \\
\text { of my major }\end{array}$ & 15.3 & 27.7 & 57.0 \\
\hline & $\begin{array}{l}\text { I have a positive affection } \\
\text { for my major. }\end{array}$ & 13.2 & 28.2 & 58.6 \\
\hline & $\begin{array}{l}\text { I am satisfied with the } \\
\text { overall situation of } \\
\text { my major }\end{array}$ & 19.5 & 23.5 & 57.0 \\
\hline & I like my major in general & 14.2 & 20.8 & 65.1 \\
\hline \multicolumn{5}{|l|}{ Behavior } \\
\hline & $\begin{array}{l}\text { I often read literature } \\
\text { related to my major }\end{array}$ & 31.3 & 27.0 & 41.7 \\
\hline & $\begin{array}{l}\text { I often complete } \\
\text { profession coursework in a } \\
\text { timely and serious manner }\end{array}$ & 8.0 & 13.2 & 78.9 \\
\hline & $\begin{array}{l}\text { I can listen carefully to } \\
\text { professional courses }\end{array}$ & 6.6 & 12.9 & 80.5 \\
\hline & $\begin{array}{l}\text { I spend a lot of time on } \\
\text { professional learning }\end{array}$ & 12.5 & 24.5 & 63.0 \\
\hline & $\begin{array}{l}\text { I am persistent in studies } \\
\text { of my major }\end{array}$ & 11.0 & 22.9 & 66.2 \\
\hline & $\begin{array}{l}\text { I actively participate in } \\
\text { extracurricular activities } \\
\text { related to the major }\end{array}$ & 13.4 & 21.1 & 65.5 \\
\hline \multicolumn{5}{|l|}{ Fitness } \\
\hline & $\begin{array}{l}\text { I have a fine profession } \\
\text { cogitation }\end{array}$ & 10.3 & 37.9 & 51.8 \\
\hline & $\begin{array}{l}\text { My disposition matches } \\
\text { the major }\end{array}$ & 12.8 & 30.9 & 56.4 \\
\hline & $\begin{array}{l}\text { The major I have learned } \\
\text { can reflect my strengths }\end{array}$ & 15.2 & 42.9 & 41.9 \\
\hline & $\begin{array}{l}\text { I feel at ease studying } \\
\text { this major }\end{array}$ & 29.7 & 32.4 & 37.9 \\
\hline
\end{tabular}

the students themselves ought to have local household registration for more than 3 consecutive years; (3) participants take the college entrance examination and obtain a qualified performance to meet the admission requirement of the RTME programme.

After admission, students are required to sign an employment agreement with the medical universities (colleges) and local health administrative department, promising that they will serve the local township hospitals for 6 years after graduation. The government would waive the related tuition fee for the students and provide them with living allowance during their school career in designated medical universities (colleges). Students who break the agreement will be refunded tuition that has been waived and compensate for the liquidated damages. The breach of contract will be recorded in the personal integrity file and physician integrity management.

\section{Abbreviations}

DASS-21: Depression Anxiety Stress Scale-21: PIQUS: Professional Identity Questionnaire for Undergraduate Students; RTME: Rural-oriented Tuition-waived Medical Education; RTMS: Rural-oriented Tuition-waived Medical Student

\section{Acknowledgments}

We sincerely thank the teaching staff and students whose consent and contributions made this study possible.

\section{Funding}

The study was funded by the Major Educational Reform Project of Education Department of Anhui Province (2016jyxm0520).

\section{Availability of data and materials}

The datasets analyzed during the current study are available from the corresponding author on reasonable request.

\section{Authors' contributions}

YY and FH collaboratively designed the study, both making substantial intellectual contributions. LW analyzed the data and drafted the manuscript together with $Y Y$, and $C J, C Z$ and $F H$ revised the manuscript. JZ, HX and $J L$ all contributed in interpreting the data. LW, YY, CJ and CZ all contributed in collecting the data. LW and YY contributed equally. All authors approved the final version and agreed to be accountable for all aspects of the work.

\section{Ethics approval and consent to participate}

This study was approved by the Ethical Committee of Anhui Medical University, China. All participants signed a written informed consent form prior to participating.

\section{Consent for publication}

Not applicable.

\section{Competing interests}

The authors declare that they have no competing interests.

\section{Publisher's Note}

Springer Nature remains neutral with regard to jurisdictional claims in published maps and institutional affiliations.

\section{Author details}

${ }^{1}$ Department of Epidemiology and Biostatistics, School of Public Health, Anhui Medical University, No. 81 Meishan Road, Shushan Districts, Hefei 230032, Anhui, China. 'Department of Public Health and General Medicine, Anhui University of Chinese Medicine, 103 Meishan Road, Shushan District, Hefei 230038, Anhui, China. ${ }^{3}$ School of Nursing, BengBu Medical College, 
2600 East Sea Avenue, Longzi Lake District, Bengbu 233030, Anhui, China. ${ }^{4}$ Department of Teaching Center for Preventive Medicine, School of Public Health, Anhui Medical University, 81 Meishan Road, Shushan District, Hefei 230032, Anhui, China. ${ }^{5}$ Central Laboratory of Preventive Medicine, School of Public Health, Anhui Medical University, 81 Meishan Road, Shushan District, Hefei 230032, Anhui, China.

Received: 17 January 2019 Accepted: 13 May 2019

Published online: 13 June 2019

\section{References}

1. Li X, Cochran C, Lu J, Shen J, Hao C, Wang Y, et al. Understanding the shortage of village doctors in China and solutions under the policy of basic public health service equalization: evidence from Changzhou. Int J Health Plann Manage. 2015;30:42-55.

2. Sun J, Luo H. Evaluation on equality and efficiency of health resources allocation and health services utilization in China. Int J Equity Health. 2017;16:127.

3. National Bureau of Statistics of China. Available from: http://www.stats.gov. cn/. Accessed 14 Oct 2018

4. Yip WC, Hsiao WC, Chen W, Hu S, Ma J, Maynard A. Early appraisal of China's huge and complex health-care reforms. Lancet. 2012;379:833-42.

5. Audibert M, Mathonnat J, Pelissier A, Huang XX, Ma A. Health insurance reform and efficiency of township hospitals in rural China: an analysis from survey data. China Econ Rev. 2013;27:326-38.

6. Liu X, Zhao S, Zhang M, Hu D, Meng Q. The development of rural primary health care in china's health system reform. J Asian Public Policy. 2015;8:88-101.

7. Zheng J, Li J, Jiang X, Zhang B. Sustaining health workforce recruitment and retention in township hospitals: a survey on 110 directors of township hospitals. Front Med. 2015;9:239-50.

8. Hu D, Chen CK, Zhang C, Huang MY, Wang JY, Jia ZL, et al. Policy implementation of targeted admission medical education program in rural areas [Chinese]. Chin J Health Policy. 2018;9:28-33.

9. Holden MD, Buck E, Luk J, Ambriz F, Boisaubin EV, Clark MA, et al. Professional identity formation: creating a longitudinal framework through TIME (transformation in medical education). Acad Med. 2015;90:761-7.

10. Wald HS. Professional identity (trans) formation in medical education: reflection, relationship, resilience. Acad Med. 2015;90:701-6.

11. Barr J, Bull R, Rooney K. Developing a patient focused professional identity: an exploratory investigation of medical students' encounters with patient partnership in learning. Adv Health Sci Educ. 2015;20:325-38.

12. Langendyk V, Hegazi I, Cowin L, Johnson M, Wilson I. Imagining alternative professional identities: reconfiguring professional boundaries between nursing students and medical students. Acad Med. 2015;90:732-7.

13. Sun L, Gao Y, Yang J, Zang XY, Wang YG. The impact of professional identity on role stress in nursing students: a cross-sectional study. Int J Nurs Stud. 2016;63:1-8.

14. Nabirye RC, Brown KC, Pryor ER, Maples EH. Occupational stress, job satisfaction and job performance among hospital nurses in Kampala, Uganda. J Nurs Manag. 2011:19:760-8.

15. Nyirenda M, Mukwato P. Job satisfaction and attitudes towards nursing care among nurses working at Mzuzu central Hospital in Mzuzu, Malawi. Malawi Med J. 2016;28:159-66.

16. Cowin LS, Johnson M, Craven RG, Marsh HW. Causal modeling of self-concept, job satisfaction, and retention of nurses. Int J Nurs Stud. 2008;45:1449-59.

17. Sabanciogullari S, Dogan S. Relationship between job satisfaction, professional identity and intention to leave the profession among nurses in Turkey. J Nurs Manag. 2015;23:1076-85.

18. Monrouxe LV, Bullock A, Tseng HM, Wells SE. Association of professional identity, gender, team understanding, anxiety and workplace learning alignment with burnout in junior doctors: a longitudinal cohort study. BM Open. 2017;7:e017942.

19. Dyrbye LN, Thomas MR, Shanafelt TD. Systematic review of depression anxiety, and other indicators of psychological distress among U.S. and Canadian medical students. Acad Med. 2006:81:354-73.

20. Andrews B, Wilding JM. The relation of depression and anxiety to life-stress and achievement in students. Br J Psychol. 2004:95:509-21.

21. Akvardar Y, Demiral Y, Ergor G, Ergor A. Substance use among medical students and physicians in a medical school in Turkey. Soc Psychiatry Psychiatr Epidemiol. 2004;39:502-6.
22. Osama M, Islam MY, Hussain SA, Masroor SM, Burney MU, Masood MA, et al. Suicidal ideation among medical students of Pakistan: a cross-sectional study. J Forensic Legal Med. 2014;27:65-8.

23. Qin PB. The characteristics and correlation study of college students' specialty identity [Chinese]. Master thesis: Southwest University; 2009.

24. Gong X, Xie XY, Xu R, Luo YJ. Psychometric properties of the Chinese version of DASS-21 in Chinese college students [Chinese]. Chin J Clin Psychol. 2010;18:443-6.

25. Li J, Liu Y, Chen LL. Study on specialty identify and learning motivation of free medical oriented students [Chinese]. Chin Health Serv Manag. 2014;31:765-7.

26. Wang SL, Li J, Liu HY, Zhang FB, Huang MY. Comparative analysis on professional identity in directed medical students and general medical students of clinical medicine [Chinese]. Med Educ Res Pract. 2018:26:74-6.

27. Mann KV. Theoretical perspectives in medical education: past experience and future possibilities. Med Educ. 2011;45:60-8.

28. Dornan T, Boshuizen H, King N, Scherpbier A. Experience-based learning: a model linking the processes and outcomes of medical students' workplace learning. Med Educ. 2007;41:84-91.

29. Pitkala KH, Mantyranta T. Professional socialization revised: medical students' own conceptions related to adoption of the future physician's role--a qualitative study. Med Teach. 2003;25:155-60.

30. Apker J, Eggly S. Communicating professional identity in medical socialization: considering the ideological discourse of morning report. Qual Health Res. 2004;14:411-29.

31. Clandinin DJ, Cave MT. Creating pedagogical spaces for developing doctor professional identity. Med Educ. 2008;42:765-70.

32. Sapkota BP, Amatya A. What factors influence the choice of urban or rural location for future practice of Nepalese medical students? A cross sectional descriptive study. Hum Resour Health. 2015;13:84.

33. Serneels P, Montalvo JG, Pettersson G, Lievens T, Butera JD, Kidanu A. Who wants to work in a rural health post? The role of intrinsic motivation, rural background and faith-based institutions in Ethiopia and Rwanda. Bull World Health Organ. 2010;88:342-9.

34. Agyei-Baffour P, Kotha SR, Johnson JC, Gyakobo M, Asabir K, Kwansah J, et al. Willingness to work in rural areas and the role of intrinsic versus extrinsic professional motivations - a survey of medical students in Ghana. BMC Med Educ. 2011:11:56.

35. Shamsuddin K, Fadzil F, Ismail WS, Shah SA, Omar K, Muhammad NA, et al. Correlates of depression, anxiety and stress among Malaysian university students. Asian J Psychiatr. 2013;6:318-23.

36. Aboalshamat $K$, Hou XY, Strodl E. Psychological well-being status among medical and dental students in Makkah, Saudi Arabia: a cross-sectional study. Med Teach. 2015;37(sup1):S75-81

37. Saadi TA, Addeen SZ, Turk T, Abbas F, Alkhatib M. Psychological distress among medical students in conflicts: a cross-sectional study from Syria. BMC Med Educ. 2017:17:173.

38. Fawzy M, Hamed SA. Prevalence of psychological stress, depression and anxiety among medical students in Egypt. Psychiatry Res. 2017:255:186-94.

39. Moutinho IL, Maddalena NC, Roland RK, Lucchetti AL, Tibirica SH, Ezequiel OD, et al. Depression, stress and anxiety in medical students: a crosssectional comparison between students from different semesters. Rev Assoc Méd Bras. 2017;63:21-8.

40. Bøe T, Skogen JC, Sivertsen B, Hysing M, Petrie KJ, Dearing E, et al. Economic volatility in childhood and subsequent adolescent mental health problems: a longitudinal population-based study of adolescents. BMJ Open. 2017;7:e017030

Ready to submit your research? Choose BMC and benefit from:

- fast, convenient online submission

- thorough peer review by experienced researchers in your field

- rapid publication on acceptance

- support for research data, including large and complex data types

- gold Open Access which fosters wider collaboration and increased citations

- maximum visibility for your research: over $100 \mathrm{M}$ website views per year

At $\mathrm{BMC}$, research is always in progress.

Learn more biomedcentral.com/submissions 